\title{
Poly Acrylic Acid Ethyl Acrylate as Smart Carrier for Rebar Inhibitor Delivery in Alkaline Condition
}

\author{
Lijuan Feng ${ }^{*}$, Meirong Li, Shanshan Zhang, Haibo Lei, Xin Cui \\ Weifang University of Science \& Technology, Weifang, 262700, China \\ *2jfeng@alum.imr.ac.cn
}

\begin{abstract}
With ethyl acrylate, acrylic acid as monomers, an intelligent carrier material (PAE) was synthesized, and its swelling properties at different $\mathrm{pH}$ values, its cycle characteristics as well as its release control performance for inhibitors in alkaline solution were studied. The results indicate that the synthesized material is sensitive to $\mathrm{pH}$ and has excellent cycle performance which is suitable for controlling drug delivery in the $\mathrm{pH}$ range from 10 to11.
\end{abstract}

Keywords-acrylic acid; ethyl acrylate; pH sensitivity; drug delivery; rebar inhibitor

\section{INTRODUCTION}

Reinforced concrete structures are widely used in various construction fields by virtue of their excellent structural performance and durability [1]. However, corrosion of reinforcement has induced many instances of premature failure of reinforced concrete components world-wide [2, 3]. It has been reported that rebar corrosion occurs only when the $\mathrm{pH}$ of the environment is decreased to or below11.The degradation of concrete structure due to steel rebar corrosion has become a serious problem and resulted in heavy socio-economic burden for many industrial departments. Application of corrosion inhibitors during the concrete casting process is always considered to be an effective and economical solution and has been used in more and more countries $[4,5]$. However, the waste of resources is a big problem during the application process of rebars inhibitors. On the other hand, some traditional inhibitors have an adverse affect on the environment. Therefore, to control the delivery of rebar inhibitors has an important economic and practical sense and this can be achieved by using $\mathrm{pH}$ sensitive materials. Investigations by Yang Yuxia [6] have indicated that poly acrylic acid derivates has $\mathrm{pH}$ sensitivity and are potential inhibitor carrier. Thus, in the work described in this paper, a polymer using poly acrylic acid and ethyl acrylate as monomers was synthesized and its $\mathrm{pH}$ sensitivity, cycle characteristics and rebar inhibitor delivery control properties in alkaline media was investigated.

\section{EXPERIMENTAL}

\section{A. Preparation of poly acrylic acid ethyl acrylate(PAE)}

The acrylic acid and ethyl acrylate monomers with the ratio of 1:1 were dissolved in anhydrous ethanol. Then distilled water, crosslinking agent, namely, $\mathrm{N}, \mathrm{N}$ '- methylene bisacrylamide and the initiator $\mathrm{NaHSO}_{3}$ was added into the reactor, mixed uniformly and sealed in the reactor for $24 \mathrm{~h}$ in an water bath with the temperature of $25{ }^{\circ} \mathrm{C}$. The prepared polymer was taken out of the reactor and washed 3 times with distilled water to remove unreacted, crosslinking agent and initiator, then it was cut into thin slices after immersion in the distilled water at room temperature for $12 \mathrm{~h}$, Finally, the dried polymer was placed in a drying oven with the temperature of $50{ }^{\circ} \mathrm{C}$ to constant weight for experimental use.

\section{B. Solution preparation}

The buffer solutions with the $\mathrm{pH}$ values of 7 and 8 were prepared by $0.2 \mathrm{~mol} / \mathrm{L} \mathrm{Na}_{2} \mathrm{HPO}_{4}$ solution and 0.3 $\mathrm{mol} / \mathrm{L} \mathrm{NaH} \mathrm{PO}_{4}$ solution, the one with the $\mathrm{pH}$ value of 9 was prepared with $0.05 \mathrm{~mol} / \mathrm{L}$ borax solution and $0.2 \mathrm{~mol} / \mathrm{L}$ solution of boric acid. $0.1 \mathrm{~mol} / \mathrm{L} \mathrm{Na}_{2} \mathrm{CO}_{3}$ solution and $0.1 \mathrm{~mol} / \mathrm{L} \mathrm{NaHCO}_{3}$ solution configurated buffer solutions of $\mathrm{pH} 10$ and 11 .Saturated $\mathrm{Ca}(\mathrm{OH})_{2}$ solution was used to be the solution of $\mathrm{pH}$ 12.6.The solution with the $\mathrm{pH}$ value of 1 was prepared by diluting concentrated hydrochloric acid. All the $\mathrm{pH}$ values of the solutions were determined using PHS-25 digital $\mathrm{pH}$ meter accurately.

\section{Determination of the equilibrium swelling ratio}

The equilibrium swelling properties could be determined by weight method. After immersion in the buffer solutions of different $\mathrm{pH}$ for 7 days, PAE samples were taken out of the solutions and the moisture on their surfaces were removed with filter paper. In this case, the wet weight could be obtained by weighing the sample and noted M1. Then the sample was put into the drying oven to constant weight at $50{ }^{\circ} \mathrm{C}$, and the dry wet could obtained, namely, M2. Then according to the equation SR= (M1M2) $/ \mathrm{M} 2 \times 100(\%)$, the equilibrium swelling properties could be measured.

\section{Electrochemical experiments}

The carbon steel samples ( $\varnothing 8 \mathrm{~mm} \times 10 \mathrm{~mm}$ ) were prepared by the same steel rebar $(0.15 \% \mathrm{C} ; 0.15 \% \mathrm{Si}$; $0.44 \% \mathrm{Mn} ; 0.30 \% \mathrm{P} ; 0.03 \% \mathrm{~S}$ and balance Fe). Except for an exposed area of $0.502 \mathrm{~cm}^{2}$, the rest part was embedded in epoxy resin. Prior to experiments, all specimens were gradually ground with emery paper to 800 grit. Before the electrochemical measurements, the carbon steel samples were classified to three group and respectively immersed 
in three types of saturated $\mathrm{Ca}(\mathrm{OH})_{2}$ solution of which the $\mathrm{pH}$ was adjusted to 11 using $\mathrm{NaHCO}_{3}$. The three types of solutions were: blank ( with no inhibitors); with rebar inhibitor or with PAE carrying rebar inhibitor. The amounts of rebar inhibitors employed were both $0.1 \mathrm{mg} / \mathrm{L}$. Electrochemical tests were performed on the Parstat 2273 system (Princeton Applied Research) facilitated with a three-electrode jacketed test instrument. A large platinum plate was used as counter electrode. The reference electrode was saturated $\mathrm{KCl}$ calomel electrode. The electrochemical impedance spectra were collected in the frequency range $100 \mathrm{kHz}$ to $10 \mathrm{mHz}$ at the OCP using a $10 \mathrm{mV}$ sinusoidal potential perturbation.

All the experiments were carried out at room temperature and all the reagents used are of AR degree.

\section{RESUlts AND DisCUSSION}

\section{A. $p H$ sensitivity tests}

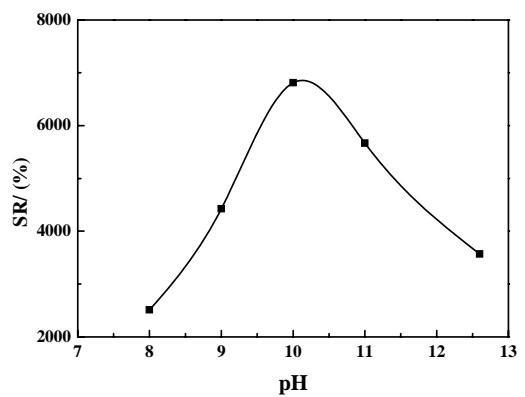

Figure 1. SR of PAE in solutions with different $\mathrm{pH}$ values

Fig.1 shows the SR evolution of PAE with the pH. It is clear that PAE is sensitive to $\mathrm{pH}$ in alkaline environment. At low $\mathrm{pH}$ range, the SR of PAE increased with the increasing $\mathrm{pH}$ value which is ascribed to that the dissociation degree of - $\mathrm{COOH}$ groups are increased with increasing $\mathrm{pH}$ value, and cause the negative charges increasing in the polymer chain, thus, its volume increases with the increasing $\mathrm{pH}$ value due to the electrostatic repulsion.[7] However, when the $\mathrm{pH}$ value is higher than 10 , all the -COOH groups have been dissociated, meanwhile, the cations gathered in the negative polymer chain increase with the increasing $\mathrm{pH}$ due to the Coulomb effect and the electrostatic repulsion of the polymer chain is weakened, leading to the decrease of SR. The $\mathrm{pH}$ sensitive properties of PAE entitle it to be an excellent carrier material for rebar inhibitor delivery control. In the initial stage when the concrete is casted, the $\mathrm{pH}$ value of the service environment is $12-13$, and the volume of the PAE is small that the rebar inhibitor is wrapped in the carrier. However, when the $\mathrm{pH}$ value of the concrete decreases to 11 , the rebar inhibitors can be released and suppress the initiation of steel rebar corrosion, thus, the inhibition effect of rebar inhibitor can be maximized.

\section{B. Cycle performance determination}

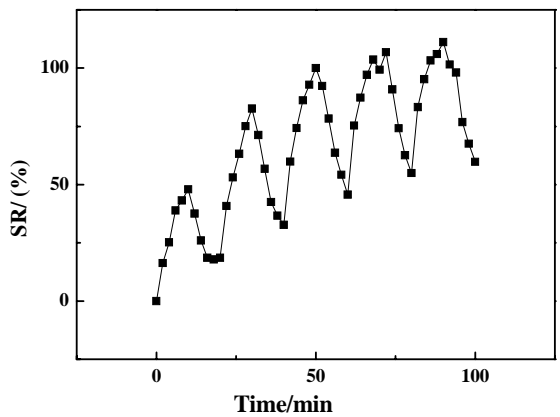

Figure 2. Dynamical change of $\mathrm{PAE}$ in solutions of $\mathrm{pH}=1$ and $\mathrm{pH}=12.5$.

In order to test the usability and stability of PAE, cycle performance determination were conducted by measuring the weight of PAE in the solutions of $\mathrm{pH}=1$ and $\mathrm{pH}=12.6$ alternately. Firstly, PAE was put in the hydrochloric acid solution of $\mathrm{pH}=1$, and the weight of PAE was measured each 2 min. 10 minutes later, then it was transferred to the saturated $\mathrm{Ca}(\mathrm{OH})_{2}$ solution with the $\mathrm{pH}$ value of $\mathrm{pH}=12.6$. These processes were repeated until $100 \mathrm{~min}$. Then the swelling dynamical change of PAE could be obtained, as shown in Fig.2. It can be seen from Fig. 2 that PAE is shrinking in acidic medium and is swelling in alkaline environment. As analyzed previously, it is related to ionization of $-\mathrm{COOH}$ groups[6,7]. The cyclic tests showed that the $\mathrm{pH}$ response properties of this material exhibit good reproducibility, however, the overall SR showed an increasing trend due to the long equilibrium swelling time. Yet, the excellent reproducibility of the swelling performance of the material at different cyclic period has suggested that PAE is very stable and its $\mathrm{pH}$ response properties can be reversible.

\section{Rebar inhibitor delivery control properties of PAE}

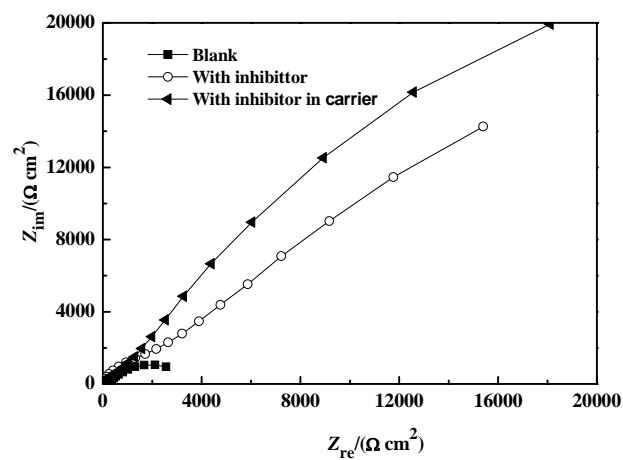

Figure 3. Electrochemical impedance spectra (Nyquist plots) of carbon steel samples in different solutions

Fig. 3 depicts the electrochemical impedance spectra of the steel electrodes in different solutions. It is notable that the capacitive arc radius of the steel sample immersed in the blank solution is very small, indicating the sample 
suffers serious corrosion. However, for the systems either with rebar inhibitor or with PAE carrying rebar inhibitor, the capacitance arc radius of the steel samples are much larger, which are both one order of magnitude greater than the blank one, indicating the corrosion resistances of steel samples are significantly enhanced by the inhibitor. These results should be ascribed to that the inhibitors can be adsorbed on the steel surface and form a protective layer which inhibited the corrosion of the steel samples. [8, 9] Furthermore, compared to the steel sample in the system only with rebar inhibitor, the capacitance arc radius of the steel sample is larger in the system with PAE, illustrating the excellent rebar inhibitor control properties of PAE.

\section{CONCLUSIONS}

A $\mathrm{pH}$ sensitive smart material was prepared using acrylic acid, acrylate as monomers. The synthesized material is very stable and has excellent cycle properties, which is suitable for controlling drug release in the systems that dug delivery is in the range from 10 to11. Electrochemical experiments confirm its effectiveness in controlling rebar inhibitor releasing.

\section{ACKNOWLEDGEMENTS}

The research work was supported by Promotive Research Fund for Excellent Young and Middle-aged Scientisits of Shandong Province No. BS2014CL029.

\section{REFERENCES}

[1] Gürten, A.A., Kayakirilmaz, K. , Erbil, M.,The effect of thiosemicarbazide on corrosion resistance of steel reinforcement in concrete. Construction and Building Materials, 21(3): pp.669$676,2007$.

[2]Hyman, A. E., Inspection, repair and rehabilitation of concrete structures due to corrosion. International Journal of Materials \& Product Technology, 23(3-4): pp.309-337, 2005.

[3] Söylev, T. A., Richardson, M. G., Corrosion inhibitors for steel in concrete: State-of-the-art report. Construction and Building Materials, 22(4): pp.609-622. 2008.

4] Lijuan Feng, Huaiyu Yang, Fuhui Wang, Experimental and theoretical studies for corrosion inhibition of carbon steel by imidazoline derivative in $5 \% \mathrm{NaCl}$ saturated $\mathrm{Ca}(\mathrm{OH})_{2}$ solution, Electrochimica Acta, 58(0):pp.427-436, 2011.

[5]Xin Zhou, Huaiyu Yang, Fuhui. Wang,[BMIM]BF4 ionic liquids as effective inhibitor for steel rebar in alkaline chloride solution. Electrochimica Acta,56 (2011):pp.4268-4275.

[6]Yang Yuxia,Yang Huaiyu, preparation of polyacrylic acid type hydrogel and its $\mathrm{pH}$ sensitive behavior in alkaline solution, Chinese journal of materials research,26(1),pp.85-90,2012.

[7] Shiratori S. S. and Rubner, M. F., pH-Dependent Thickness Behavior of Sequentially Adsorbed Layers of Weak Polyelectrolytes, Macromolecules, 33(2000), pp.4213-4219.

[8] Elsener, B., Zurich, E.in: M. Raupach, B. Elsener, R. Polder, J. Mietz (Eds.), Corrosion of Reinforcement in Concrete: Mechanisms, Monitoring, Inhibitors and Rehabilitation Techniques, 1st ed., Woodhead Publishing Limited, Cambridge England, p. 170, 2007.

[9]Kern, P., Landolt, D. ,Adsorption of organic corrosion inhibitors on iron in the active and passive state. A replacement reaction between inhibitor and water studied with the rotating quartz crystal microbalance. Electrochimica Acta, 47 (4): pp.589-598, 2001. 